\title{
Associations of Exercise Tolerance and Clinical Parameters in Japanese Patients With Chronic Obstructive Pulmonary Disease: Impact of Skeletal Muscle
}

Hiroki Tashiro ( $\nabla$ si3222@cc.saga-u.ac.jp )

Saga University

Koichiro Takahashi

Saga University

Masahide Tanaka

Saga University

Hironori Sadamatsu

Saga University

Yuki Kurihara

Saga University

Ryo Tajiri

Saga University

Ayako Takamori

Saga University

Hiroyuki Naotsuka

Saga University

Hiroki Imaizumi

Saga University

Shinya Kimura

Saga University

Naoko Sueoka-Aragane

Saga University

\section{Research Article}

Keywords: rcise tolerance, cardiopulmonary exercise testing, skeletal muscle, COPD

Posted Date: February 17th, 2021

DOI: https://doi.org/10.21203/rs.3.rs-199971/v1 
License: (c) (i) This work is licensed under a Creative Commons Attribution 4.0 International License. Read Full License

Version of Record: A version of this preprint was published at Scientific Reports on August 5th, 2021. See the published version at https://doi.org/10.1038/s41598-021-95413-9. 
1 Title

2 Associations of exercise tolerance and clinical parameters in Japanese patients with chronic

3 obstructive pulmonary disease: Impact of skeletal muscle

4

\section{Authors}

6 Hiroki Tashiro ${ }^{1}$, Koichiro Takahashi ${ }^{1}$, Masahide Tanaka ${ }^{1}$, Hironori Sadamatsu ${ }^{1}$, Yuki Kurihara ${ }^{1}$,

7 Ryo Tajiri ${ }^{2}$, Ayako Takamori ${ }^{2}$, Hiroyuki Naotsuka ${ }^{3}$, Hiroki Imaizumi ${ }^{3}$, Shinya Kimura ${ }^{1}$, Naoko

8 Sueoka-Aragane ${ }^{1}$

9

10 Affiliations

$11{ }^{1}$ Division of Hematology, Respiratory Medicine and Oncology, Department of Internal

12 Medicine, Faculty of Medicine, Saga University, Saga, Japan

$13{ }^{2}$ Clinical Research Center, Saga University Hospital, Saga, Japan

$14{ }^{3}$ Advanced Comprehensive Functional Recovery Center, Saga University Hospital, Saga, Japan 15

16 Corresponding author: Hiroki Tashiro $\mathrm{MD}, \mathrm{PhD}$

17 Division of Hematology, Respiratory Medicine and Oncology, Department of Internal

18 Medicine, Faculty of Medicine, Saga University

19 5-1-1 Nabeshima, Saga, Saga Prefecture, 849-8501, Japan

20 Phone: +81-952-34-2369; Fax: +81-952-34-2017

21 E-mail: si3222@cc.saga-u.ac.jp

22 


\section{Abstract}

\section{Background}

25 Decreasing exercise tolerance is one of the key features related to a poor prognosis in patients

26 with chronic obstructive pulmonary disease (COPD). Cardiopulmonary exercise testing (CPET)

27 is useful for evaluating exercise tolerance. The present study was performed to clarify the

28 correlation between exercise tolerance and clinical parameters, focusing especially on the cross-

29 sectional area (CSA) of skeletal muscle.

\section{Methods}

31 The present study retrospectively investigated 69 patients with COPD who underwent CPET.

32 The correlations between oxygen uptake $\left(\dot{\mathrm{V}}_{2}\right)$ at peak exercise and clinical parameters of

33 COPD, including skeletal muscle area measured using single-section axial computed

34 tomography $(\mathrm{CT})$, were evaluated.

\section{$35 \quad$ Results}

36 The COPD assessment test score $(\rho=-0.35, \mathrm{p}=0.02)$ and the CSA of the pectoralis muscles ( $\rho$

$37=0.32, \mathrm{p}=0.02$ ) were weakly correlated with $\dot{\mathrm{V}}_{\mathrm{O} 2}$ at peak exercise. In addition, forced

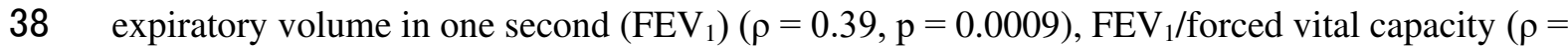

$390.33, p=0.006)$, and the CSA of the erector spinae muscles $(\rho=0.34, p=0.009)$ were

40 correlated with $\dot{\mathrm{V}}_{\mathrm{O} 2}$ at peak exercise.

\section{Conclusions}

42 Decreased $\mathrm{FEV}_{1}$ and loss of skeletal muscles, especially anti-gravity muscles, are correlated

43 with a low level of exercise tolerance in COPD patients.

44

45 


\section{$46 \quad$ Keywords}

47 exercise tolerance, cardiopulmonary exercise testing, skeletal muscle, COPD

48 
50 Chronic pulmonary obstructive disease (COPD) is a common respiratory disease, with a

51 reported global prevalence of 251 million cases ${ }^{1}$, and it is considered a life-threatening disease

52 with decreasing pulmonary function and airflow limitation ${ }^{2}$.

53 Recently, factors related to a poor prognosis of COPD patients, including mortality and

54 exacerbations, are becoming understood as evidence increases. For example, low-level physical

55 activity, percent predicted forced expiratory volume in one second $\left(\% \mathrm{FEV}_{1}\right), 6$-minute walk distance, body mass index (BMI), and a high frequency of exacerbations are significantly associated with mortality in COPD patients ${ }^{3,4}$. We and others have also reported that low-level pulmonary function, exercise tolerance (including 6-minute walk distance and exercise-induced desaturation), and BMI are correlated with a high frequency of exacerbations ${ }^{5-8}$, indicating that evaluations of exercise tolerance and body composition, in addition to pulmonary function, are important for predicting the clinical course of COPD.

\section{Decreasing exercise tolerance, normally measured by the 6-minute walk test or} cardiopulmonary exercise testing (CPET), is one of the important clinical features related to a poor prognosis in COPD patients ${ }^{3,9,10}$, and with CPET one can evaluate exercise tolerance with exertional ventilatory parameters precisely and safely ${ }^{11,12}$. For example, oxygen uptake $\left(\dot{\mathrm{V}}_{\mathrm{O} 2}\right)$ at peak exercise, which represents exercise tolerance, is significantly correlated with $\mathrm{FEV}_{1}$ and $\% \mathrm{FEV}_{1}$ reflecting the severity of COPD ${ }^{13,14}$. Notably, with CPET, one can detect physical problems including cardiac dysfunction and functional skeletal muscle disorders during the test, which contributes to rapid initiation of treatment ${ }^{15}$.

$$
\text { Weight loss is a common systemic characteristic of patients with COPD }{ }^{16} \text {, and skeletal muscle }
$$
loss has greater impact on the severity of COPD than decreased BMI ${ }^{17}$. Radiological analysis of skeletal muscles on computed tomography (CT) is a useful procedure for quantitation without onerous physical intervention ${ }^{18,19}$, and the cross-sectional area (CSA) of skeletal muscle on single-slice axial CT is significantly correlated with a poor prognosis in COPD patients ${ }^{20,21}$. In 
75 addition, the CSA of the erector spinae muscles (ECMs), which are anti-gravity muscles, but not

76 of the pectoralis muscles (PMs), is significantly associated with mortality in Japanese patients

77 with COPD ${ }^{21}$. Obviously, skeletal muscles are important for exercise tolerance, but the impact

78 of exertional ventilatory parameters on CPET compared to clinical parameters in patients with

79 COPD is not fully understood.

80 In the present real-world study, correlations between exercise tolerance indicated by $\mathrm{V}_{2}$ at

81 peak exercise and clinical parameters including skeletal muscle area were examined in Japanese

82 patients with COPD. Decreases of $\mathrm{FEV}_{1}$ and $\mathrm{FEV}_{1} / \mathrm{FVC}$ are significantly correlated with a low

83 level of exercise tolerance, and, importantly, skeletal muscle area, especially of the ECMs as

84 anti-gravity muscles, is more correlated with $\dot{\mathrm{V}}_{\mathrm{O} 2}$ at peak exercise than PM area on CT imaging.

85 These data suggest that decreased $\mathrm{FEV}_{1}$ and $\mathrm{FEV}_{1} / \mathrm{FVC}$ are correlated with decreased exercise

86 tolerance and loss of skeletal muscles, especially the anti-gravity muscles, that contribute to a

87 low level of exercise tolerance.

88 
Results

\section{$91 \quad$ Clinical baseline characteristics of COPD patients}

92 In the present study, 69 COPD patients (66 males, 3 females) who underwent CPET were enrolled; their average age was 71.1 years, BMI was $21.4 \mathrm{~kg} / \mathrm{m}^{2}$, and smoking history was 67.6 pack-years. GOLD stages I - IV were 12 (17.4\%), 27 (39.1\%), 25 (36.2\%), and 5 (7.2\%), respectively; mMRC dyspnea scale scores $(0$ - 4) were $5(7.2 \%), 18(26.1 \%), 27(39.1 \%), 16$ (23.2\%), and $3(4.3 \%)$, respectively. The average COPD assessment test score available for 41 patients was 16.8, and the average 6-minute walk distance for 48 patients was $386.1 \mathrm{~m}$. For medications, long-acting muscarinic antagonist (LAMA) or long acting $\beta_{2}$ adrenergic agonist (LABA) monotherapy was given to $5(7.2 \%)$ patients. LABA-LAMA and inhaled corticosteroid (ICS)-LABA combination therapies were given to $19(27.5 \%)$ and $9(13.0 \%)$ patients, respectively. Triple combination therapy was given to $19(27.5 \%)$ patients. Five patients $(7.2 \%)$ were not given respiratory medications. On pulmonary function testing, $\% \mathrm{VC}$ and $\% \mathrm{FVC}$ were $100.4 \%$ and $95.2 \%$, respectively. $\mathrm{FEV}_{1}, \mathrm{FEV}_{1} / \mathrm{FVC}$, and $\% \mathrm{FEV}_{1}$ were $1.35 \mathrm{~L}, 60.2 \%$, and $65.9 \%$, respectively. The average DLco was $65.9 \%$. On CT, PM ${ }_{\mathrm{CSA}}$ and $\mathrm{ECM}_{\mathrm{CSA}}$ were $24.7 \mathrm{~cm}^{2}$ and $27.1 \mathrm{~cm}^{2}$, respectively (Table 1 ).

106

\section{Parameters of cardiopulmonary exercise testing} $\mathrm{ml} / \mathrm{min}$ at peak exercise. Body weight-adjusted $\dot{\mathrm{V}}_{\mathrm{O} 2}$ was $5.3 \mathrm{ml} / \mathrm{min} / \mathrm{kg}$ at rest and 16.2

$110 \mathrm{ml} / \mathrm{min} / \mathrm{kg}$ at peak exercise. $\mathrm{V}_{\mathrm{T}}$ and $\mathrm{V}_{\mathrm{E}}$ were $773.2 \mathrm{ml}$ and $12.9 \mathrm{~L} / \mathrm{min}$ at rest and $1245.7 \mathrm{ml}$ and

$11136.6 \mathrm{~L} / \mathrm{min}$ at peak exercise, respectively. $\dot{\mathrm{V}}_{\mathrm{E}} / \dot{\mathrm{V}}_{\mathrm{CO} 2}$, which reflects pulmonary clearance of $\mathrm{CO}_{2}$

$112{ }^{22}$, was 49.3 at rest and 41.1 at peak exercise. $V_{D} / V_{T}$, which reflects the efficacy of pulmonary

113 gas exchange, was 0.28 at rest and 0.26 at peak exercise. The respiratory rate was 17.7

114 breaths/min at rest and 30.5 breaths/min at peak exercise (Table 2). 
116 Correlations between $\dot{\mathrm{V}}_{\mathrm{O} 2}(\mathrm{ml} / \mathrm{min} / \mathrm{kg})$ at peak exercise and other parameters on CPET

117 and the 6-minute walk distance

118 Because $\dot{\mathrm{V}}_{\mathrm{O} 2}(\mathrm{ml} / \mathrm{min})$ is affected by body weight differences, $\dot{\mathrm{V}}_{\mathrm{O} 2}$ adjusted by body weight

$119(\mathrm{ml} / \mathrm{min} / \mathrm{kg})$ at peak exercise is considered a precise marker for exercise tolerance ${ }^{22}$. Therefore,

120 the evaluation focused on that and its correlations with other CPET parameters and the 6-minute

121 walk distance. $\dot{\mathrm{V}}_{\mathrm{O} 2}$ at peak exercise was significantly correlated with $\dot{\mathrm{V}}_{\mathrm{E}} / \dot{\mathrm{V}}_{\mathrm{CO} 2}$ at rest $(\rho=-0.46$,

$122 \mathrm{p}<0.0001)$ and at peak exercise $(\rho=-0.45, \mathrm{p}<0.0001), \mathrm{V}_{\mathrm{D}} / \mathrm{V}_{\mathrm{T}}$ at rest $(\rho=-0.36, \mathrm{p}=0.002)$ and

123 at peak exercise $(\rho=-0.53, \mathrm{p}<0.0001)$, respiratory rate at rest $(\rho=-0.35, \mathrm{p}=0.003)$ and at

124 peak exercise $(\rho=-0.33, p=0.006)$, and the 6-minute walk distance $(\rho=0.74, p<0.0001)$

125 (Table 3, Supplementary Fig. S1a online). These data showed that $\dot{\mathrm{V}}_{\mathrm{O} 2}(\mathrm{ml} / \mathrm{min} / \mathrm{kg})$ at peak

126 exercise reflected exercise tolerance in COPD patients.

127

128 Comparisons of correlations between $\dot{\mathbf{V}}_{\mathrm{O} 2}(\mathrm{ml} / \mathrm{min} / \mathrm{kg})$ at peak exercise and clinical

129 parameters of COPD including skeletal muscle area

130 To clarify the factors correlated with exercise tolerance as reflected by $\dot{\mathrm{V}}_{\mathrm{O} 2}(\mathrm{ml} / \mathrm{min} / \mathrm{kg})$ at peak 131 exercise, correlation analysis between $\dot{\mathrm{V}}_{\mathrm{O} 2}(\mathrm{ml} / \mathrm{min} / \mathrm{kg})$ at peak exercise and clinical parameters

132 of COPD including skeletal muscle area was performed. Age, BMI, \% VC, $\% \mathrm{FVC}, \% \mathrm{FEV}_{1}$, and

133 DLco were not significantly correlated with $\dot{\mathrm{V}}_{\mathrm{O} 2}$ at peak exercise. The COPD assessment test

134 score $\left(\rho=-0.35, p=0.02\right.$, Supplementary Fig. S1b online) and $\operatorname{PM}_{\mathrm{CSA}}(\rho=0.32, p=0.02$, Fig.

135 1c) were weakly correlated with $\dot{\mathrm{V}}_{\mathrm{O} 2}$ at peak exercise. $\operatorname{FEV}_{1}(\rho=0.39, \mathrm{p}=0.0009$, Fig. 1a),

$136 \operatorname{FEV}_{1} / \mathrm{FVC}\left(\rho=0.33, p=0.006\right.$, Fig. 1b), and $\operatorname{ECM}_{\mathrm{CSA}}(\rho=0.34, p=0.009$, Fig. $1 d)$ were

137 correlated with $\dot{\mathrm{V}}_{\mathrm{O} 2}$ at peak exercise (Table 4). Examining the difference in $\dot{\mathrm{V}}_{\mathrm{O} 2}$ at peak exercise

138 by COPD stage, COPD stage III and IV patients had significantly lower levels of $\dot{\mathrm{V}}_{\mathrm{O} 2}$ at peak

139 exercise than stage II patients (Fig. 2a). Additionally, examining the difference in $\dot{\mathrm{V}}_{\mathrm{O} 2}$ at peak

140 exercise by the mMRC dyspnea scale score, patients with an mMRC scale score of 3 had a

141 significantly lower $\dot{\mathrm{V}}_{2}$ at peak exercise than those with an mMRC scale score of 0 (Fig. 2b). 
142 For other parameters on CPET, $\dot{\mathrm{V}}_{\mathrm{E}} / \dot{\mathrm{V}}_{\mathrm{CO} 2}$ at peak exercise was significantly correlated with BMI

$143(\rho=-0.33, p=0.007)$, the COPD assessment test score $(\rho=0.58, p<0.0001)$, DLco $(\rho=-0.42$,

$144 \mathrm{p}=0.001), \mathrm{PM}_{\mathrm{CSA}}(\rho=-0.31, \mathrm{p}=0.02)$, and $\operatorname{ECM}_{\mathrm{CSA}}(\rho=-0.31, \mathrm{p}=0.02)$. In addition, $\mathrm{V}_{\mathrm{D}} / \mathrm{V}_{\mathrm{T}}$ at

145 peak exercise was significantly correlated with age $(\rho=0.34, p=0.005)$, BMI $(\rho=-0.28, p=$

146 0.02), the COPD assessment test score $(\rho=0.41, p=0.009), \% \mathrm{VC}(\rho=-0.28, p=0.02), \mathrm{FEV}_{1}$

$147(\rho=-0.42, \mathrm{p}=0.004), \mathrm{FEV}_{1} / \mathrm{FVC}(\rho=-0.36, \mathrm{p}=0.003), \% \mathrm{FEV}_{1}(\rho=-0.27, \mathrm{p}=0.03), \mathrm{PM}_{\mathrm{CSA}}(\rho$

$148=-0.31, \mathrm{p}=0.02)$, and $\operatorname{ECM}_{\mathrm{CSA}}(\rho=-0.27, \mathrm{p}=0.03)($ Supplementary Table S1 online).

149

150 


\section{Discussion}

152 In the present real-world study, the exercise tolerance of COPD patients was evaluated by

153 CPET, and it was confirmed that $\dot{\mathrm{V}}_{\mathrm{O} 2}$ at peak exercise was significantly correlated with 6-

154 minute walk distance and other CPET parameters, such as $\dot{\mathrm{V}}_{\mathrm{E}} / \dot{\mathrm{V}}_{\mathrm{CO} 2}, \mathrm{~V}_{\mathrm{D}} / \mathrm{V}_{\mathrm{T}}$, and respiratory rate,

155 which suggested that $\dot{\mathrm{V}}_{\mathrm{O} 2}$ at peak exercise is a useful marker of exercise tolerance for COPD

156 patients. The analysis of correlation coefficients showed that the COPD assessment test, $\mathrm{FEV}_{1}$,

$157 \mathrm{FEV}_{1} / \mathrm{FVC}, \mathrm{PM} \mathrm{CSA}$, and $\mathrm{ECM}_{\mathrm{CSA}}$ were correlated with $\dot{\mathrm{V}}_{\mathrm{O} 2}$ at peak exercise. Additionally,

158 ECM $_{\mathrm{CSA}}$, reflecting anti-gravity muscles, was more correlated with $\dot{\mathrm{V}}_{\mathrm{O} 2}$ at peak exercise than

$159 \mathrm{PM}_{\mathrm{CSA}}$, showing that the loss of skeletal muscles, especially anti-gravity muscles, contributed to

160 a low level of exercise tolerance.

161 Loss of exercise tolerance is an important and widely recognized clinical manifestation of

$162 \operatorname{COPD}^{15,22}$. With respect to the mechanisms, exercise-induced dyspnea with dynamic

163 pulmonary hyperinflation and desaturation of oxygen, which is a representative manifestation of

164 COPD, contributes to a low threshold of exhaustion with the early appearance of anaerobic

165 metabolites in skeletal muscles during exercise ${ }^{22}$. Thus, $\dot{\mathrm{V}}_{\mathrm{O} 2}$ at peak exercise on CPET, which is

166 determined by cellular $\mathrm{O}_{2}$ demand and the maximal rate of $\mathrm{O}_{2}$ transport, is considered a useful

167 marker of exercise tolerance in COPD patients ${ }^{15}$. Diaz et al analyzed 52 patients with mild to

168 severe COPD, and air-flow limitation, which reflects the presence of dynamic hyperinflation,

169 was found to be significantly associated with $\dot{\mathrm{V}}_{\mathrm{O} 2}$ at peak exercise ${ }^{12}$. Moreover, Kagawa et al

170 analyzed 294 patients with COPD who underwent CPET, and they found that decreased FEV 1

171 was associated with a low $\dot{\mathrm{V}}_{2}$ at peak exercise ${ }^{13}$. These reports showed that limitation of

172 exercise tolerance predicted by decreased $\dot{\mathrm{V}}_{\mathrm{O} 2}$ at peak exercise is an important phenotype of

173 COPD, as shown in the current study (Table 4, Fig. 1a, Fig. 1b). The severity of COPD

174 predicted by $\% \mathrm{FEV}_{1}$ is also related to the decrease of exercise tolerance, and Yamamoto et al

175 reported that $\dot{\mathrm{V}}_{\mathrm{O} 2}$ at peak exercise was significantly higher in COPD patients in GOLD stages I

176 and II than in those in GOLD stages III and IV ${ }^{14}$. The current results also showed that the level 
177 of $\dot{\mathrm{V}}_{\mathrm{O} 2}$ at peak exercise tended to be decreased depending on the GOLD stage, except for stage I

178 (Fig. 2a), although the correlation between $\dot{\mathrm{V}}_{\mathrm{O} 2}$ at peak exercise and $\% \mathrm{FEV}_{1}$ was weak (Table

$1794)$.

180 Loss of skeletal muscles with bodyweight reduction, called sarcopenia, is also an important

181 characteristic of COPD patients ${ }^{20,23,24}$. Reduction of fat-free mass containing skeletal muscle is

182 associated with mortality in patients with COPD ${ }^{25}$. In addition, a previous report showed that

183 COPD patients with decreased skeletal muscles, calculated by bioelectrical impedance analysis,

184 walked a significantly shorter distance on the incremental shuttle walk test, which is another

185 index of exercise tolerance, than those with preserved skeletal muscles ${ }^{26}$. With respect to the

186 mechanisms, loss of skeletal muscles causes increased $\mathrm{O}_{2}$ demand as exercise intensity increases

187 and earlier reaching of the anaerobic threshold with metabolic acidosis and increased lactate,

188 which limits exercise tolerance in patients with $\mathrm{COPD}^{27,28}$. The present study showed that

189 skeletal muscle area including $\mathrm{PM}_{\mathrm{CSA}}$ and $\mathrm{ECM}_{\mathrm{CSA}}$ was significantly correlated with $\dot{\mathrm{V}}_{\mathrm{O} 2}$ at peak

190 exercise, which is consistent with these data (Table 4, Fig. 1c, Fig. 1d).

191 Importantly, the present results showed that $\mathrm{ECM}_{\mathrm{CSA}}$, representing anti-gravity muscles, was

192 more correlated with $\dot{\mathrm{V}}_{\mathrm{O} 2}$ at peak exercise than $\mathrm{PM}_{\mathrm{CSA}}$ (Table 4), which suggests that loss of

193 skeletal muscle might be heterogeneous, depending on the anatomical role of the muscle groups.

194 Indeed, a prospective, observational study of 130 COPD patients showed that ECM $_{\mathrm{CSA}}$ is

195 correlated with clinical parameters of COPD and more correlated with all-cause mortality than

$196 \mathrm{PM}_{\mathrm{CSA}}{ }^{20}$. In addition, a longitudinal, 10-year observational study showed that loss of ECM $\mathrm{CSA}_{\mathrm{C}}$,

197 but not $\mathrm{PM}_{\mathrm{CSA}}$, significantly increased the hazard ratio of mortality ${ }^{21}$, because physical activity

198 is the strongest predictor of the prognosis of COPD patients ${ }^{3}$, and sedentary behavior, which

199 affects the anti-gravity muscles, is particularly important in $\mathrm{COPD}^{29,30}$; thus, anti-gravity

200 muscles might contribute to exercise tolerance in patients with COPD, as seen in the present

201 study. 
202 Notably, other gas exchange parameters on CPET such as $\dot{\mathrm{V}}_{\mathrm{E}} / \dot{\mathrm{V}}_{\mathrm{CO} 2}$ and $\mathrm{V}_{\mathrm{D}} / \mathrm{V}_{\mathrm{T}}$ at peak exercise

203 were associated with the clinical data of COPD, including skeletal muscle area (Supplementary

204 Table S1 online). These parameters were reported to be significantly higher in patients with

205 COPD than in healthy individuals ${ }^{31}$, and $\dot{\mathrm{V}}_{\mathrm{E}} / \dot{\mathrm{V}}_{\mathrm{CO} 2}$, which reflects decreased pulmonary

206 clearance of $\mathrm{CO}_{2}$ during exercise, was correlated with BMI, \% FEV ${ }_{1}$, and DLco, in addition to

207 skeletal muscle areas. Moreover, $\mathrm{V}_{\mathrm{D}} / \mathrm{V}_{\mathrm{T}}$, which reflects worse pulmonary gas exchange efficacy,

208 was correlated with age, $\mathrm{BMI}, \% \mathrm{VC}, \mathrm{FEV}_{1}, \mathrm{FEV}_{1} / \mathrm{FVC}$, and $\% \mathrm{FEV}_{1}$, in addition to skeletal

209 muscle areas. Interestingly, the COPD assessment test score was strongly correlated with these

210 parameters, suggesting that $\dot{\mathrm{V}}_{\mathrm{E}} / \dot{\mathrm{V}}_{\mathrm{CO} 2}$ and $\mathrm{V}_{\mathrm{D}} / \mathrm{V}_{\mathrm{T}}$ might reflect COPD-related symptoms

211 (Supplementary Table S1 online).

212 There are several limitations of the present study. First, correlations with physical activity were

213 not evaluated. Second, correlations were evaluated using clinical parameters of COPD and

214 skeletal muscle area, which acted as confounding factors. Partial correlation coefficients were

215 calculated using factors including the COPD assessment test score, $\mathrm{FEV}_{1}, \mathrm{FEV}_{1} / \mathrm{FVC}, \% \mathrm{FEV}_{1}$,

216 DLco, $\mathrm{PM}_{\mathrm{CSA}}$, and $\mathrm{ECM}_{\mathrm{CSA}}$, and the COPD assessment test score, $\mathrm{PM}_{\mathrm{CSA}}$, and $\mathrm{ECM}_{\mathrm{CSA}}$ were

217 more correlated with $\dot{\mathrm{VO}}_{2}$ at peak exercise than $\mathrm{FEV}_{1}, \mathrm{FEV}_{1} / \mathrm{FVC}, \% \mathrm{FEV}_{1}$, and DLco after

218 adjustment (data not shown), suggesting that skeletal muscle area might be more important than

219 pulmonary function for exercise tolerance. Finally, the present study involved patients at a

220 single hospital with limited ethnic diversity and a small sample size. To confirm the validity of

221 the present results, multicenter, prospective studies with a larger number of patients should be

222 performed. 


\section{Conclusions}

225 The present study showed that decreases in $\mathrm{FEV}_{1}$ and $\mathrm{FEV}_{1} / \mathrm{FVC}$ are significantly correlated 226 with a low level of exercise tolerance and skeletal muscle area, and the area of the ECMs, as 227 anti-gravity muscles, is more correlated with $\dot{\mathrm{V}}_{\mathrm{O} 2}$ at peak exercise than the area of the PMs.

228 These data suggest that decreased pulmonary function and loss of skeletal muscles, especially 229 anti-gravity muscles, contribute to the low level of exercise tolerance in patients with COPD. 230 


\section{$232 \quad$ Patients and setting}

233 The medical records of 69 patients diagnosed with COPD who underwent CPET at the Saga

234 University Hospital between 2009 and 2020 were retrospectively reviewed. All patients

235 satisfied the definition criteria of the Global Initiative for Chronic Obstructive Lung Disease

236 (GOLD). Briefly, patients were confirmed to have $\mathrm{FEV}_{1} / \mathrm{FEV}<0.7$ after using a bronchodilator,

237 a smoking index > 10 pack years, and symptoms including chronic cough, sputum, and dyspnea.

238 Patients with either a current or a previous diagnosis of asthma were excluded. For patient

239 information, age at the time CPET was performed was used, and clinical parameters including

240 BMI, modified Medical Research Council (mMRC) dyspnea scale, COPD assessment test, 6-

241 minute walk test, medication record, and pulmonary function at the time closest to when CPET

242 was performed (within \pm 3 months) were evaluated. Thus, 41 patients who underwent the COPD

243 assessment test and 48 patients who underwent the 6-minute walk test were analyzed.

244 Medications were selected at each physician's discretion. This study was approved by the ethics

245 committee of Saga University Hospital (approval number: 2020-11-R-03, approval date: Jan 27,

246 2021) and was performed in accordance with the 1964 Declaration of Helsinki. Informed

247 consent was obtained for participants in the form of opt-out on the web-site. Those who rejected 248 were excluded.

249

250 Cardiopulmonary Exercise Testing

251 A symptom-limited cycle ergometer (Strength Ergo 8, Mitsubishi Electric Engineering, Japan)

252 was used for CPET. Each patient wore a mask, and breath was analyzed using a gas analyzer

253 (Cpex-1, Inter Reha; Japan); $\dot{\mathrm{V}}_{\mathrm{O} 2}$, expiratory tidal volume $\left(\mathrm{V}_{\mathrm{T}}\right)$, minute ventilation $\left(\mathrm{V}_{\mathrm{E}}\right)$,

254 ventilatory equivalent for carbon dioxide $\left(\dot{\mathrm{V}}_{\mathrm{E}} / \dot{\mathrm{V}}_{\mathrm{CO} 2}\right)$, dead space to tidal volume ratio $\left(\mathrm{V}_{\mathrm{D}} / \mathrm{V}_{\mathrm{T}}\right)$,

255 and breathing frequency at rest and at peak exercise were evaluated. Oxygen saturation, blood pressure, and the electrocardiogram were measured during the test. In the exercise protocol, pre- 
exercise resting measurements were obtained within the steady state period for more than 3

258 minutes. Incremental testing was then started by increasing the load by $10 \mathrm{~W}$ per minute. The

259 examination was continued until exhaustion or above the predicted maximum heart rate or

260 blood pressure, and showing electrocardiographic changes such as ST segment depression of

261 greater than $2 \mathrm{~mm}$ and a short run of premature ventricular contractions. Dyspnea intensity was

262 evaluated by a 10-point modified Borg category-ratio scale at rest and every 1 minute after

263 initiation of the incremental load test. The data generated were measured breath-by-breath and

264 as 30-second averages at rest and during exercise.

265

\section{CT scan acquisition and analysis}

267 Chest CT for analysis of the pectoralis and erector spinae muscles that was performed most

268 closely to the time of CPET (within \pm 3 years) was also selected; the average time between

269 CPET and chest CT was 198 days. Consequently, 57 patients were examined. For quantitative

270 analysis, the CSAs of the pectoralis muscles $\left(\mathrm{PM}_{\mathrm{CSA}}\right)$ and the erector spinae muscles (ESM $\left.\mathrm{CSA}_{\mathrm{A}}\right)$

271 were evaluated referring to the previously described method ${ }^{20,24,32}$. Briefly, left and right areas

272 of $\mathrm{PM}_{\mathrm{CSA}}$ identified by the superior aspect of the aortic arch and $\mathrm{ESM}_{\mathrm{CSA}}$ identified by the

273 superior aspect of the $12^{\text {th }}$ thoracic vertebrae on CT imaging reconstructed using the mediastinal

274 setting were identified and shaded manually. Finally, the sum of the left and right muscle areas

275 was examined. The measurements were performed by two pulmonary physicians independently.

\section{Statistical analysis}

278 For correlation analysis, Spearman's rank correlation coefficients between exercise tolerance

279 parameters such as $\dot{\mathrm{V}}_{\mathrm{O} 2}, \dot{\mathrm{V}}_{\mathrm{E}} / \dot{\mathrm{V}}_{\mathrm{CO} 2}, \mathrm{~V}_{\mathrm{D}} / \mathrm{V}_{\mathrm{T}}$, breathing frequency, and 6-minute walk distance, and

280 clinical parameters including age, BMI, COPD assessment test score, \%VC, \% FVC, FEV ,

$281 \mathrm{FEV}_{1} / \mathrm{FVC}, \% \mathrm{FEV}_{1}$, diffusing capacity of the lung for carbon monoxide (DLco), $\mathrm{PM}_{\mathrm{CSA}}$, and

282 ECM $_{\mathrm{CSA}}$ were calculated to determine whether they were zero. Differences of $\mathrm{V}_{2}$ at peak 
283 exercise depending on GOLD stages and the mMRC dyspnea scale were analyzed by the Steel-

284 Dwass method. Quantitative data are presented as means \pm standard deviation (SD);

285 significance was considered a $\mathrm{p}$ value less than 0.05 . Statistical analysis was performed with

286 JMP Pro version 14.2.0 software (SAS Institute Inc., Cary, NC, USA).

287 


\section{Data availability}

289 The datasets used and analyzed during the current study are available from the corresponding 290 author on reasonable request.

291

292 
294 1. Halpin DMG, et al. The GOLD Summit on chronic obstructive pulmonary disease in 295 low- and middle-income countries. Int J Tuberc Lung Dis. 23, 1131-41. (2019).

2962 2. Hasegawa W, et al. Factors affecting mortality following emergency admission for 297 chronic obstructive pulmonary disease. BMC Pulm Med. 14, 151. (2014).

298 3. Waschki B, et al. Physical activity is the strongest predictor of all-cause mortality in patients with COPD: a prospective cohort study. Chest. 140, 331-42. (2011).

4. Prudente R, et al. Predictors of mortality in patients with COPD after 9 years. Int $J$ Chron Obstruct Pulmon Dis. 13, 3389-98. (2018).

5. Tashiro H, et al. Clinical features of Japanese patients with exacerbations of chronic obstructive pulmonary disease. BMC Pulm Med. 20, 318. (2020).

6. Kim EK, et al. Impact of Body Mass Index Change on the Prognosis of Chronic Obstructive Pulmonary Disease. Respiration. 1-11. (2020).

7. Chang $\mathrm{CH}$, et al. Factors Associated with Exercise-Induced Desaturation in Patients with Chronic Obstructive Pulmonary Disease. Int J Chron Obstruct Pulmon Dis. 15, 2643-52. (2020).

8. Herer B, Chinet T. Acute exacerbation of COPD during pulmonary rehabilitation: outcomes and risk prediction. Int J Chron Obstruct Pulmon Dis. 13, 1767-74. (2018).

9. Laboratories ATSCoPSfCPF. ATS statement: guidelines for the six-minute walk test. Am J Respir Crit Care Med. 166, 111-7. (2002).

10. Horie J, et al. Validation of Clinical Characteristics and Effectiveness of Pulmonary Rehabilitation in a COPD Population with Discrepancy between Exercise Tolerance and FEV1. Healthcare (Basel). 9. (2021).

11. Puente-Maestu L, et al. Use of exercise testing in the evaluation of interventional efficacy: an official ERS statement. Eur Respir J. 47, 429-60. (2016).

12. Diaz O, et al. Role of inspiratory capacity on exercise tolerance in COPD patients with and without tidal expiratory flow limitation at rest. Eur Respir J. 16, 269-75. (2000).

13. Kagawa H, et al. Dyspnea and the Varying Pathophysiologic Manifestations of Chronic Obstructive Pulmonary Disease Evaluated by Cardiopulmonary Exercise Testing With Arterial Blood Analysis. Front Physiol. 9, 1293. (2018).

14. Yamamoto Y, et al. Evaluation of Exertional Ventilatory Parameters Using Oscillometry in COPD. Int J Chron Obstruct Pulmon Dis. 15, 1697-711. (2020).

15. American Thoracic S, American College of Chest P. ATS/ACCP Statement on cardiopulmonary exercise testing. Am J Respir Crit Care Med. 167, 211-77. (2003).

16. Landbo C, et al. Prognostic value of nutritional status in chronic obstructive pulmonary disease. Am J Respir Crit Care Med. 160, 1856-61. (1999).

17. Ischaki E, et al. Body mass and fat-free mass indices in COPD: relation with variables expressing disease severity. Chest. 132, 164-9. (2007).

18. Giuliani HK, Gerstner GR, Mota JA, Ryan ED. Influence of Demographic Characteristics and Muscle Strength on the Occupational Fatigue Exhaustion Recovery Scale in Career Firefighters. J Occup Environ Med. 62, 223-6. (2020).

19. Bak SH, Kwon SO, Han SS, Kim WJ. Computed tomography-derived area and density of pectoralis muscle associated disease severity and longitudinal changes in chronic obstructive pulmonary disease: a case control study. Respir Res. 20, 226. (2019).

20. Tanimura K, et al. Quantitative Assessment of Erector Spinae Muscles in Patients with Chronic Obstructive Pulmonary Disease. Novel Chest Computed Tomography-derived Index for Prognosis. Ann Am Thorac Soc. 13, 334-41. (2016).

21. Tanabe N, et al. Associations of CT evaluations of antigravity muscles, emphysema and airway disease with longitudinal outcomes in patients with COPD. Thorax. (2020).

22. Arena R, Sietsema KE. Cardiopulmonary exercise testing in the clinical evaluation of 
patients with heart and lung disease. Circulation. 123, 668-80. (2011).

344 23. Maltais F, et al. An official American Thoracic Society/European Respiratory Society

345 statement: update on limb muscle dysfunction in chronic obstructive pulmonary disease. Am J

346 Respir Crit Care Med. 189, e15-62. (2014).

347 24. McDonald ML, et al. Quantitative computed tomography measures of pectoralis muscle

348 area and disease severity in chronic obstructive pulmonary disease. A cross-sectional study. Ann

349 Am Thorac Soc. 11, 326-34. (2014).

35025 . Vestbo J, et al. Body mass, fat-free body mass, and prognosis in patients with chronic 351 obstructive pulmonary disease from a random population sample: findings from the Copenhagen 352 City Heart Study. Am J Respir Crit Care Med. 173, 79-83. (2006).

353 26. Jones SE, et al. Sarcopenia in COPD: prevalence, clinical correlates and response to 354 pulmonary rehabilitation. Thorax. 70, 213-8. (2015).

355 27. Patessio A, et al. Comparison of gas exchange, lactate, and lactic acidosis thresholds in 356 patients with chronic obstructive pulmonary disease. Am Rev Respir Dis. 148, 622-6. (1993).

357 28. Hughson RL, Weisiger KH, Swanson GD. Blood lactate concentration increases as a 358 continuous function in progressive exercise. J Appl Physiol (1985). 62, 1975-81. (1987).

359 29. Tremblay MS, et al. Sedentary Behavior Research Network (SBRN) - Terminology 360 Consensus Project process and outcome. Int J Behav Nutr Phys Act. 14, 75. (2017).

361 30. Takahashi K, et al. First-Line Treatment with Tiotropium/Olodaterol Improves Physical 362 Activity in Patients with Treatment-Naive Chronic Obstructive Pulmonary Disease. Int J Chron 363 Obstruct Pulmon Dis. 15, 2115-26. (2020).

364 31. Elbehairy AF, et al. Pulmonary Gas Exchange Abnormalities in Mild Chronic 365 Obstructive Pulmonary Disease. Implications for Dyspnea and Exercise Intolerance. Am J Respir 366 Crit Care Med. 191, 1384-94. (2015).

36732 . Lee CS, et al. Dorsal muscle group area and surgical outcomes in liver transplantation. 368 Clin Transplant. 28, 1092-8. (2014). 


\section{$371 \quad$ Acknowledgements}

372 Not applicable

373

374 Author Contributions

375 H.T., K.T. and M.T. conceived and designed the project. H.T., Y.K., H.N. and H.I. analyzed and

376 interpreted the data. R.T. and A.T. advised the statistical analysis. H.T., K.T. and H.S. prepared

377 the manuscript with input from all other authors. S.K. and N.A. checked the prepared

378 manuscript. All authors reviewer the manuscript.

379

380 Competing interests

381 The authors declare no competing interests.

382 
383 Figure 1. Correlations between $\dot{\mathrm{V}}_{\mathrm{O} 2}$ at peak exercise and clinical parameters of COPD.

384 Correlations between $\dot{\mathrm{V}}_{\mathrm{O} 2}$ at peak exercise and (a) $\mathrm{FEV}_{1}$, (b) $\mathrm{FEV}_{1} / \mathrm{FEV}$, (c) $\mathrm{PM}_{\mathrm{CSA}}$, and (d)

$385 \quad \mathrm{ECM}_{\mathrm{CSA}}$

386

387 Abbreviations: $\dot{\mathrm{V}}_{\mathrm{O} 2}$ : oxygen uptake, COPD: chronic obstructive pulmonary disease, $\mathrm{FEV}_{1}$ :

388 forced expiratory volume in 1 second, FVC: forced vital capacity, PMCSA: cross-sectional area

389 of the pectoralis muscles, ECM $_{\mathrm{CSA}}$ : cross-sectional area of the erector spinae muscles.

390

391

392 Figure 2. Results of $\dot{\mathrm{V}}_{\mathrm{O} 2}$ by (a) GOLD stage and (b) mMRC dyspnea scale score. ${ }^{*} \mathrm{p}<0.05$

393

394

395 Abbreviations: $\dot{V}_{\mathrm{O} 2}$ : oxygen uptake, GOLD: Global Initiative for Chronic Obstructive Lung

396 Disease, mMRC: modified Medical Research Council

397

398 
Table 1. Demographics of the study participants $(n=69)$

\begin{tabular}{|c|c|}
\hline Clinical parameters & \\
\hline age (years) & $71.1 \pm 9.0$ \\
\hline gender (male/female) & $66 / 3$ \\
\hline $\operatorname{BMI}\left(\mathrm{kg} / \mathrm{m}^{2}\right)$ & $21.4 \pm 3.8$ \\
\hline smoking history (pack-year) & $67.6 \pm 33.0$ \\
\hline GOLD stage (I/II/III/IV, n) & $12 / 27 / 25 / 5$ \\
\hline mMRC dyspnea scale $(0 / 1 / 2 / 3 / 4, n)$ & $5 / 18 / 27 / 16 / 3$ \\
\hline COPD assessment test $(n=41)$ & $16.8 \pm 7.6$ \\
\hline 6-minute walk distance $(\mathrm{n}=48)(\mathrm{m})$ & $386.1 \pm 115.8$ \\
\hline Medications & \\
\hline No respiratory medication, $\mathrm{n}(\%)$ & $5(7.2 \%)$ \\
\hline LAMA or LABA alone, $\mathrm{n}(\%)$ & $17(24.6 \%)$ \\
\hline LABA-LAMA combo, $\mathrm{n}(\%)$ & $19(27.5 \%)$ \\
\hline ICS-LABA combo, $\mathrm{n}(\%)$ & $9(13.0 \%)$ \\
\hline Triple combo, n (\%) & $19(27.5 \%)$ \\
\hline Pulmonary function & \\
\hline$\% \mathrm{VC}(\%)$ & $100.4 \pm 18.4$ \\
\hline$\% \mathrm{FVC}(\%)$ & $95.2 \pm 17.5$ \\
\hline $\mathrm{FEV}_{1}(\mathrm{~L})$ & $1.35 \pm 0.59$ \\
\hline $\mathrm{FEV}_{1} / \mathrm{FVC}(\%)$ & $43.8 \pm 13.4$ \\
\hline$\% \mathrm{FEV}_{1}(\%)$ & $60.2 \pm 24.2$ \\
\hline $\operatorname{DLco}(\%)$ & $65.9 \pm 24.3$ \\
\hline Evaluation of skeletal muscle on CT $(n=57)$ & \\
\hline $\mathrm{PM}_{\mathrm{CSA}}\left(\mathrm{cm}^{2}\right)$ & $24.7 \pm 8.1$ \\
\hline $\operatorname{ECM}_{\mathrm{CSA}}\left(\mathrm{cm}^{2}\right)$ & $27.1 \pm 6.7$ \\
\hline
\end{tabular}

401 BMI; body mass index, GOLD; global initiative for chronic obstructive lung disease, mMRC;

402 modified medical research council, COPD; chronic obstructive pulmonary disease, LAMA;

403 long-acting muscarinic antagonist, LABA; long acting $\beta_{2}$ adrenergic agonist, ICS; inhaled

404 corticosteroid, VC; vital capacity, FVC; forced vital capacity, $\mathrm{FEV}_{1}$; forced expiratory volume

405 in 1 second, DLco; diffusing capacity of lung for carbon monoxide, PM $\mathrm{CSA}_{\mathrm{A}}$; cross-sectional area

406 of pectoralis muscles, ECM $\mathrm{CSA}_{\text {; }}$; cross-sectional area of erector spinae muscles. Data are

407 presented as mean \pm standard deviation. 
408 Table 2. Results of cardiopulmonary exercise testing at rest and at peak exercise $(n=69)$

\begin{tabular}{|l|c|c|}
\hline & at rest & at peak exercise \\
\hline Incremental load testing & & \\
$\dot{\mathrm{V}}_{\mathrm{O} 2}(\mathrm{ml} / \mathrm{min})$ & $295.6 \pm 68.2$ & $926.0 \pm 338.4$ \\
$\dot{\mathrm{V}}_{\mathrm{O} 2}(\mathrm{ml} / \mathrm{min} / \mathrm{kg})$ & $5.3 \pm 1.2$ & $16.2 \pm 4.7$ \\
$\mathrm{~V}_{\mathrm{T}}(\mathrm{ml})$ & $773.2 \pm 204.5$ & $1245.7 \pm 362.6$ \\
$\mathrm{~V}_{\mathrm{E}}(\mathrm{L} / \mathrm{min})$ & $12.9 \pm 2.6$ & $36.6 \pm 10.9$ \\
$\dot{\mathrm{V}}_{\mathrm{E}} / \dot{\mathrm{V}}_{\mathrm{CO} 2}$ & $49.3 \pm 8.9$ & $41.1 \pm 8.4$ \\
$\mathrm{~V}_{\mathrm{D}} / \mathrm{V}_{\mathrm{T}}$ & $0.28 \pm 0.07$ & $0.26 \pm 0.07$ \\
Breathing frequency (times $/ \mathrm{min})$ & $17.7 \pm 4.2$ & $30.5 \pm 8.1$ \\
\hline
\end{tabular}

409

$410 \dot{\mathrm{V}}_{\mathrm{O} 2}$; oxygen uptake, $\mathrm{V}_{\mathrm{T}}$; tidal volume, $\mathrm{V}_{\mathrm{E}}$; minute ventilation, $\dot{\mathrm{V}}_{\mathrm{E}} / \dot{\mathrm{V}}_{\mathrm{CO} 2}$; ventilatory equivalent

411 for carbon dioxide, $\mathrm{V}_{\mathrm{D}} / \mathrm{V}_{\mathrm{T}}$; dead space to tidal volume ratio. Data are presented as mean \pm

412 standard deviation.

413 
414 Table 3. Correlation coefficients between $\dot{\mathrm{V}}_{\mathrm{O} 2}$ at peak exercise and other CPET parameters and 415 the 6-minute walk distance

416

\begin{tabular}{|l|c|c|}
\hline & \multicolumn{2}{|c|}{$\dot{\mathrm{V}}_{\mathrm{O} 2}(\mathrm{ml} / \mathrm{min} / \mathrm{kg})$ at peak exercise } \\
\hline & $\rho$ & $\mathrm{p}$ value \\
$\dot{\mathrm{V}}_{\mathrm{E}} / \dot{\mathrm{V}}_{\mathrm{CO} 2}$ at rest & -0.46 & $<0.0001$ \\
$\dot{\mathrm{V}}_{\mathrm{E}} / \dot{\mathrm{V}}_{\mathrm{CO} 2}$ at peak exercise & -0.45 & $<0.0001$ \\
$\mathrm{~V}_{\mathrm{D}} / \mathrm{V}_{\mathrm{T}}$ at rest & -0.36 & 0.002 \\
$\mathrm{~V}_{\mathrm{D}} / \mathrm{V}_{\mathrm{T}}$ at peak exercise & -0.53 & $<0.0001$ \\
Breathing frequency at rest & -0.35 & 0.003 \\
Breathing frequency at peak exercise & -0.33 & 0.006 \\
& & \\
6-minute walk distance $(\mathrm{n}=48)$ & 0.74 & $<0.0001$ \\
\hline
\end{tabular}

$417 \dot{\mathrm{V}}_{\mathrm{O} 2}$; oxygen uptake, $\mathrm{V}_{\mathrm{T}}$; tidal volume, $\mathrm{V}_{\mathrm{E}}$; minute ventilation, $\dot{\mathrm{V}}_{\mathrm{E}} / \dot{\mathrm{V}}_{\mathrm{CO} 2}$; ventilatory equivalent

418 for carbon dioxide, $\mathrm{V}_{\mathrm{D}} / \mathrm{V}_{\mathrm{T}}$; dead space to tidal volume ratio.

419 
420 Table 4. Correlation coefficients between $\dot{\mathrm{V}}_{\mathrm{O} 2}$ at peak exercise and other CPET parameters and 421 the 6-minute walk distance

422

423

\begin{tabular}{|c|c|c|}
\hline & \multicolumn{2}{|c|}{$\dot{\mathrm{V}}_{\mathrm{O} 2}(\mathrm{ml} / \mathrm{min} / \mathrm{kg})$ at peak exercise } \\
\hline age (years) & $\begin{array}{c}\rho \\
-027\end{array}$ & $\mathrm{p}$ value \\
\hline $\operatorname{BMI}\left(\mathrm{kg} / \mathrm{m}^{2}\right)$ & 0.08 & 0.54 \\
\hline COPD assessment test & -0.35 & 0.02 \\
\hline$\% \operatorname{VC}(\%)$ & 0.19 & 0.11 \\
\hline$\% \mathrm{FVC}(\%)$ & 0.16 & 0.2 \\
\hline $\mathrm{FEV}_{1}(\mathrm{~L})$ & 0.39 & 0.0009 \\
\hline $\mathrm{FEV}_{1} / \mathrm{FVC}(\%)$ & 0.33 & 0.006 \\
\hline$\% \mathrm{FEV}_{1}(\%)$ & 0.24 & 0.05 \\
\hline $\operatorname{DLco}(\%)$ & 0.26 & 0.05 \\
\hline $\mathrm{PM}_{\mathrm{CSA}}\left(\mathrm{cm}^{2}\right)$ & 0.32 & 0.02 \\
\hline $\mathrm{ECM}_{\mathrm{CSA}}\left(\mathrm{cm}^{2}\right)$ & 0.34 & 0.009 \\
\hline
\end{tabular}

424 CPET; Cardiopulmonary exercise testing, $\dot{\mathrm{V}}_{\mathrm{O} 2}$; oxygen uptake, BMI; body mass index, COPD;

425 chronic obstructive pulmonary disease, $\mathrm{VC}$; vital capacity, FVC; forced vital capacity, $\mathrm{FEV}_{1}$;

426 forced expiratory volume in 1 second, DLco; diffusing capacity of lung for carbon monoxide,

$427 \mathrm{PM}_{\mathrm{CSA}}$; cross-sectional area of pectoralis muscles, $\mathrm{ECM}_{\mathrm{CSA}}$; cross-sectional area of erector

428 spinae muscles.

429 
Figures

Figure 1

Tashiro $\mathrm{H}$ et al,

(a)

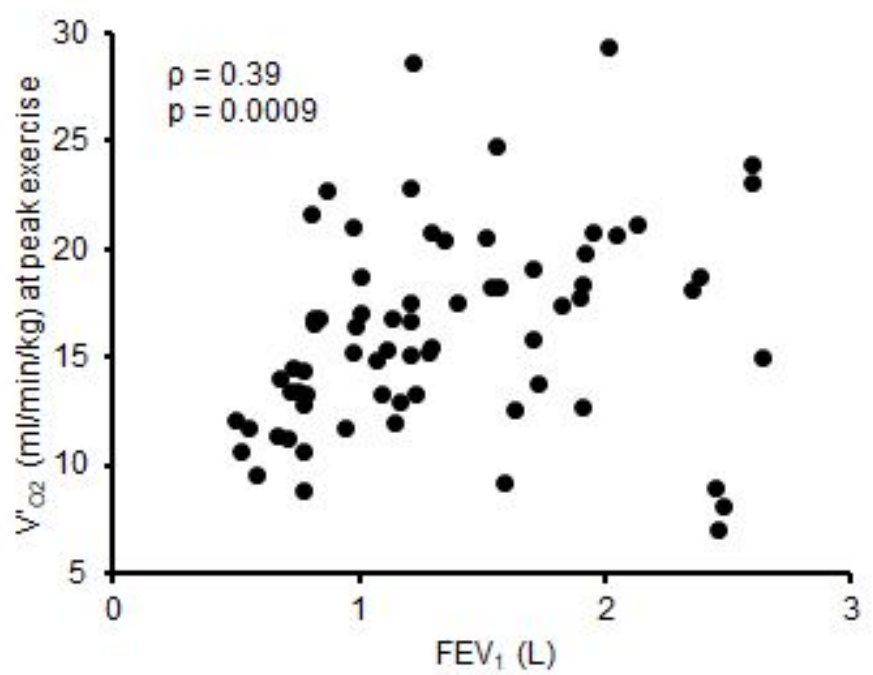

(c)

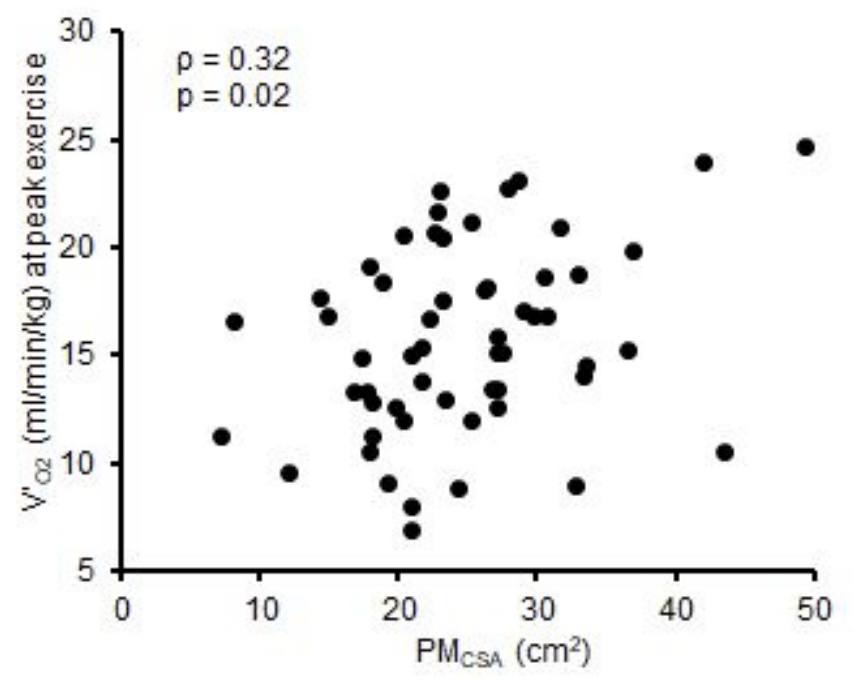

(b)

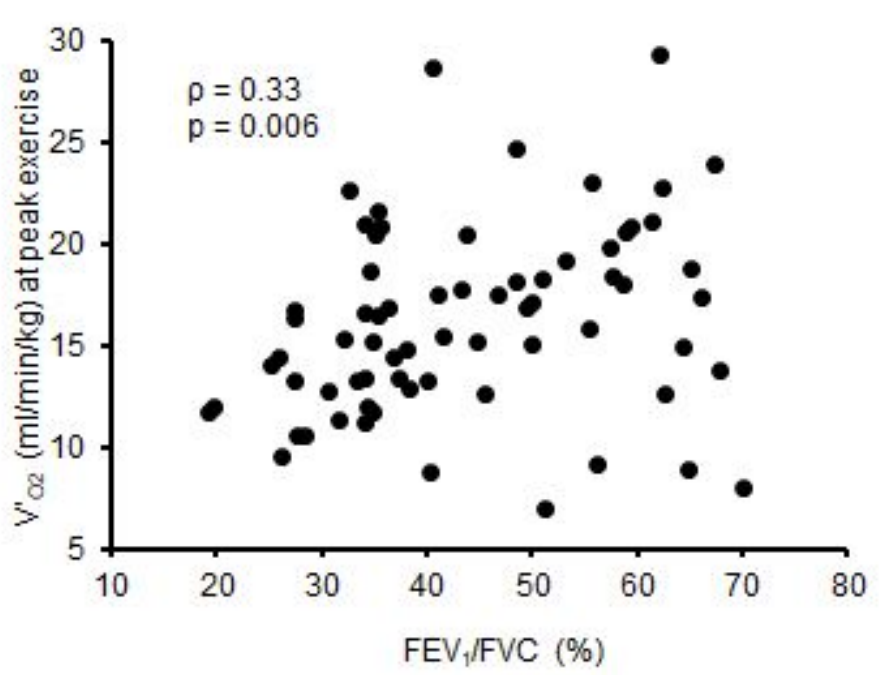

(d)

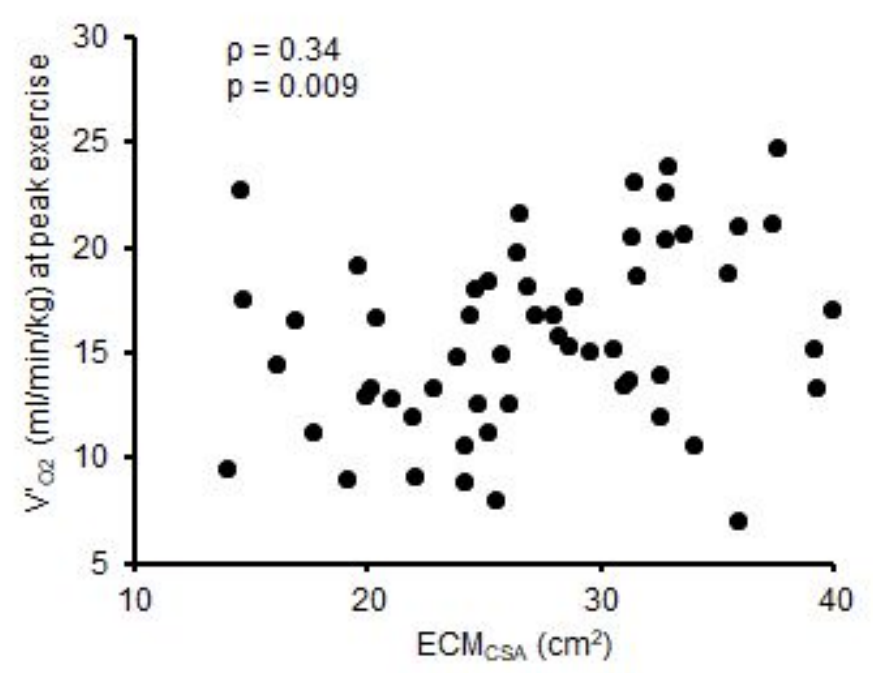

Figure 1

Correlations between $₫ \mathrm{O} 2$ at peak exercise and clinical parameters of COPD. Correlations between $₫ \mathrm{O} 2$ at peak exercise and (a) FEV1, (b) FEV1/ FEV, (c) PMCSA, and (d) ECMCSA Abbreviations: \O2: oxygen uptake, COPD: chronic obstructive pulmonary disease, FEV1: forced expiratory volume in 1 second, FVC: forced vital capacity, PMCSA: cross-sectional area of the pectoralis muscles, ECMCSA: cross-sectional area of the erector spinae muscles. 
(a)

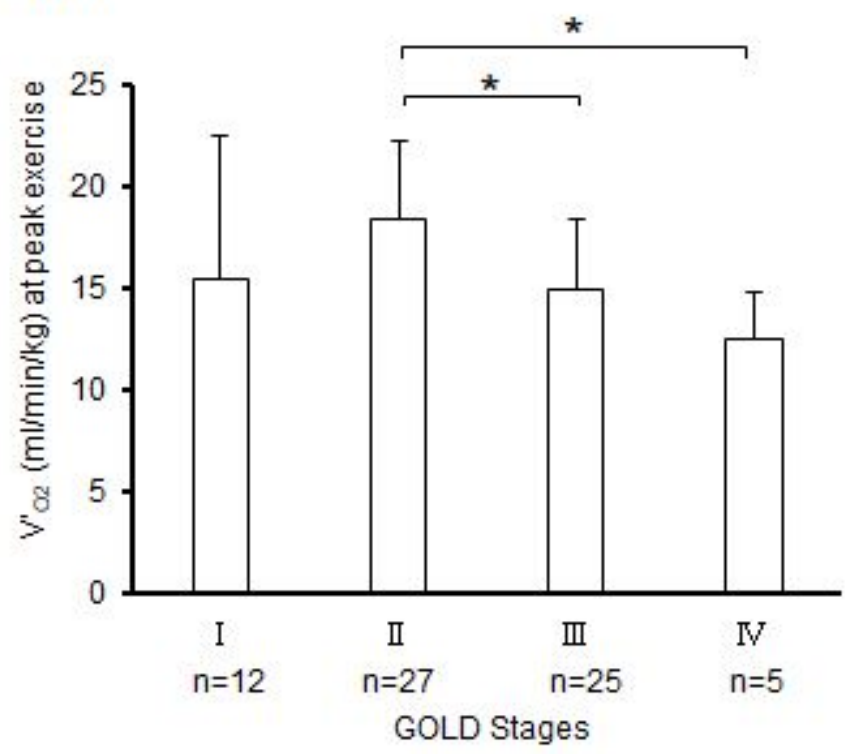

(b)

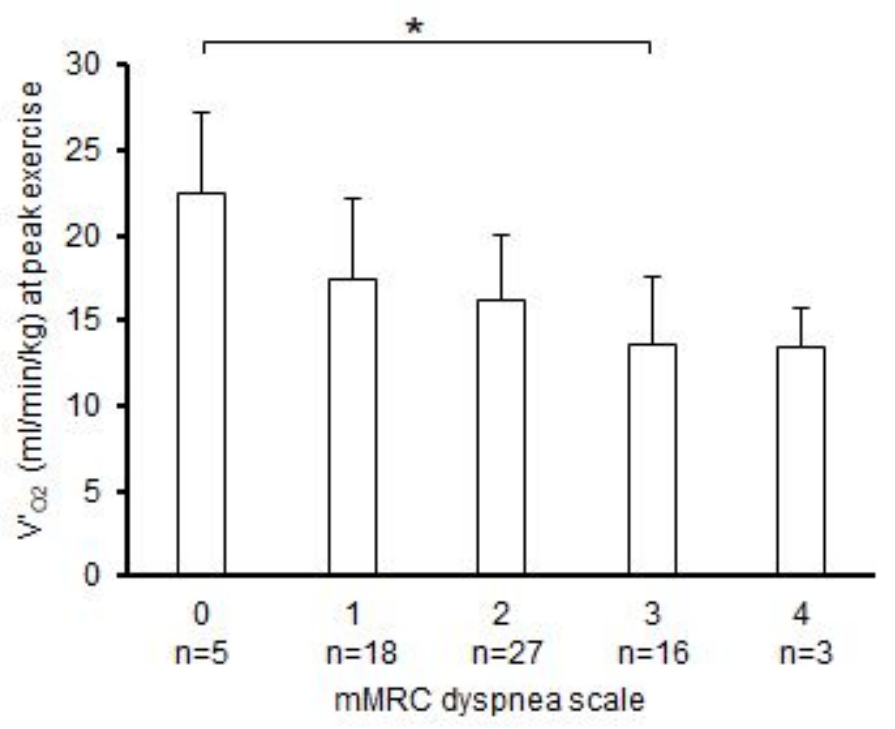

Figure 2

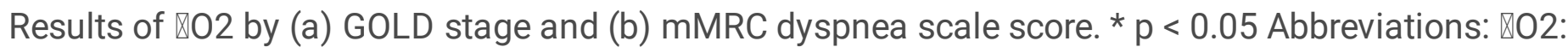
oxygen uptake, GOLD: Global Initiative for Chronic Obstructive Lung Disease, mMRC: modified Medical Research Council

\section{Supplementary Files}

This is a list of supplementary files associated with this preprint. Click to download.

- supplementaryinformation1.pptx

- supplementaryinformation2.docx 